\title{
Correction to: Understanding Emotion in Design Inspiration Contexts Through the Core Affect Model
}

\author{
Vimalkrishnan Rangarajan, Prasad S. Onkar, Alison De Kruiff, \\ and Deirdre Barron
}

Correction to:

Chapter 6 in: A. Chakrabarti et al. (eds.), Design

for Tomorrow-Volume 3, Smart Innovation, Systems

and Technologies 223,

https://doi.org/10.1007/978-981-16-0084-5_6

The book was inadvertently published with chapter author's incorrect family name. The author's name has been corrected from "Vimal Krishnan R" to "Vimalkrishnan Rangarajan". 